\title{
Long-distance Spore Transport: Vertical Sections of Spore Clouds over the Sea
}

\author{
By J. M. HIRST AND O. J. STEDMAN \\ Rothamsted Experimental Station, Harpenden, Hertfordshire \\ AND G. W. HURST \\ Meteorological Office, Bracknell, Berkshire
}

(Accepted for publication 13 March 1967)

SUMMARY

To measure the rate at which spore clouds were depleted over the sea, spores were collected with isokinetic suction impactors mounted in aircraft of the Meteorological Research Flight, Farnborough. Remote from sources able to replenish spore clouds, preferential deposition from the lower layers caused 'erosion' of the base of vertical profiles of spore concentration leaving maxi$\mathrm{ma}$ at heights between 500 and $1500 \mathrm{~m}$. To determine vertical spore distributions throughout the largest possible distance downwind of the English coast, a saw-tooth flight plan of alternating ascent and descent was used. Of four flights, two encountered favourable weather, rain interfered with sampling on one and unexpected winds across the track converted another into an unintended but interesting cross-wind section of spore distribution.

Pollens and Cladosporium spores were counted as examples of large and small spores liberated typically by day, and a composite group of spores liberated in damp air was chosen as an indicator of spores liberated mostly at night. In two flights in fine weather maximum spore concentrations occurred hundreds of miles off-shore. Diagrams showing height, distance from the coast and lines of equal spore concentration ('isospores') demonstrated discrete clouds of each marker spore type. Pollen and Cladosporium clouds were centred at approximately the same distances from the coast but with the pollen about $500 \mathrm{~m}$. lower, probably because the pollen grains sedimented faster. Maximum concentrations of the damp-air group sometimes coincided and sometimes alternated with the day-liberated groups. Known periodicities of these spores over land, surface air trajectories and previous weather, suggested that the spore clouds which the aircraft overtook over the North Sea, were the residue of those produced from the British Isles on previous days or nights. Interpretation of the results was limited by meteorological uncertainties, the geographical complexity of probable source areas, and perhaps most by changes in the number of spores crossing the coast at different times of day, which prevented accurate measurement of rates of spore deposition.

Spores of many species were recognized over the North Sea. The plant pathogens included established distant migrants such as uredospores of Puccinia graminis, which apparently originated east of the Baltic. The viability of the spores was not tested, but it seems safe to assume that distant transport is both frequent and extensive and probably important in temperate latitudes in summer. 

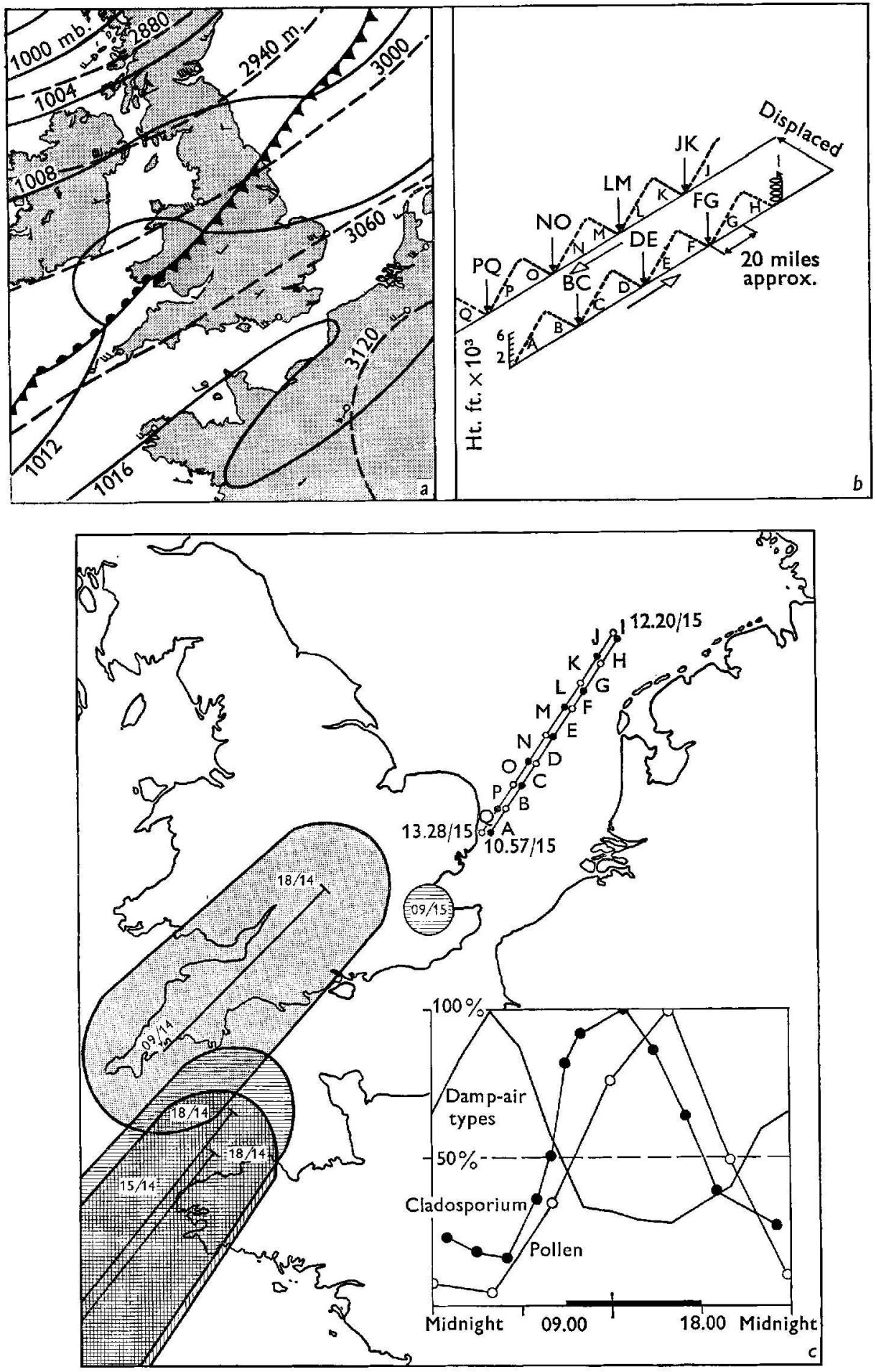

Fig. I. For legend see opposite page. 


\section{INTRODUCTION}

An earlier paper which described methods used to study vertical spore and temperature profiles and to intercept immigrant spores, showed that Puccinia graminis uredospores, the best examples of recognizable long-distance immigrants, were sometimes commonest at altitudes of $\mathrm{I}-2 \mathrm{~km}$. (Hirst, Stedman \& Hogg, 1967). Such profiles may have resulted from preferential deposition from the base of the spore cloud and it seemed that 'eroded' profiles might be typical of spores that had travelled far from their source areas. It proved impracticable to test this idea directly by sampling over a source of uredospores and then at a series of points at increasing distances downwind. We therefore attempted to test whether progressive erosion of the bottom of profiles was a feature common to all spore types during travel over non-productive regions, by estimating changes in density of common constituents of the air-spora during transport over the North Sea downwind of sources in the British Isles.

\section{METHODS}

Although the spore-sampling methods and meteorological interpretation were similar to those already described (Hirst et al. 1967) a few modifications were necessary because the object was to measure several vertical profiles to the greatest practicable distance downwind from the coast. Instead of collecting during spiral ascents and descents, which occupies much flight time, a 'saw-tooth' plan of alternate ascent and descent on constant track was used. Air traffic control regulations often dictated height and track, but when possible the aircraft climbed above the convective layer far enough inland for the first profile to be sampled over land during descent at $300 \mathrm{~m}$./ min., ending at approximately $50 \mathrm{~m}$. above sea level just clear of the coast. Instead of triplet samples preceded by a dummy (as in Hirst et al. 1967), collection was continuous with an instantaneous change-over to a new sampling drum position every minute. At the highest and lowest points a single sample was collected during level flight and a Lycopodium marker trace inserted between dummies. Further details are best introduced with the description of the flights to which they apply.

\section{RESULTS}

$$
\text { Flight I/62; 10.57-13.28 G.M.T., I5 June } 1962
$$

On I 4 June 1962 a complex depression north-west of Ireland and high pressure over the Mediterranean resulted in a broad band of south-westerly winds crossing south-

Fig. I. Weather and plan of Flight I/62. (a) Synoptic map for o0.oI, 15 June I962. Solid lines are surface isobars and corresponding winds are shown by arrows without circles (velocity, 5 knots $(9.3 \mathrm{~km}$. hr) per half feather). Dashed lines and arrows with circles show $700 \mathrm{mb}$. contours (m.) and winds at these heights. (b) Isometric plan of Flight $1 / 62$. The outward track started with an ascent $A$ then a descent $B$ and so on. Each dash indicates a sample and an equal number were taken in the spiral ascent $I$. The diagram is not to scale and for clarity the return track is displaced as shown. (c) Map of flight track and times (A began at $10.00,15$ June). Inset shows that, with typical diurnal periodicities of concentration, Cladosporium and pollen are most common between 09.00 and I 8.00 and damp-air types at night (Hirst, 1953). Shaded areas indicate probable source areas for the day-liberated spores estimated from surface trajectories of air sampled at A, vertical shading; at I, stippled and at $\mathrm{Q}$, horizontal shading. 
east England and the southern North Sea. In these areas lighter south-west winds continued during ${ }_{5}$ June as the depression moved towards Iceland and a weak ridge moving from the West began to affect the southern half of the British Isles (Fig. I $a$ ). A flight was planned with a starting-point just off East Anglia and a track of about $045^{\circ}$ parallel to the wind.

Sampling began at 10.57 (all times are G.M.T.) at a height of $60 \mathrm{~m}$. and a position north-east of Orfordness $52^{\circ} \mathrm{I}^{\prime} \mathrm{N}$, OI $^{\circ} 48^{\prime} \mathrm{E}$ (Fig. I $c$ ). The first sample was taken during level flight followed by ascent A (Fig. I $b$ ) to $1800 \mathrm{~m}$., a sample in level flight and then descent $\mathrm{B}$ ending approximately 40 miles north-east of the starting-point (all distances are quoted in nautical miles: I nautical mile $=\mathrm{I} \cdot 853 \mathrm{~km}$.). The pattern was repeated to position $54^{\circ} 15^{\prime} \mathrm{N}, 05^{\circ} 12^{\prime} \mathrm{E}$ followed by a spiral ascent I, with continuous sampling. The saw-tooth pattern was reversed during the return flight on a reciprocal track, making a total of 126 samples.

Figure $\mathrm{r} b$ distorts the length and height of the ascents and descents, in which the top and bottom of each sloping flight path were separated by 22 miles in length but by only $\mathrm{I} 800 \mathrm{~m}$. in height. However, it was convenient to ignore this and to treat each sequence of samples as if it were a separate vertical profile. Samples taken in level flight at the top and bottom of each ascent or descent were common to two adjacent profiles but because most spores occurred at low altitudes, the profiles of a descent and an ascent were paired, sharing a common $30 \mathrm{~m}$. sample, e.g. BC, DE, FG, etc. (Fig. I $b$ ). We accepted the errors incurred as a result of displacing the small catches of each high-altitude sample by approximately 20 miles. The ascent $\mathrm{A}$ was unpaired and the descent $\mathrm{H}$ was paired with the spiral ascent $\mathrm{I}$.

The temperature profiles were treated similarly and showed (Fig. 2) stable air near sea level. Above $300 \mathrm{~m}$. there was a layer of conditionally unstable air, about $1000 \mathrm{~m}$. deep at the north-east extremity of the flight but much shallower near the English coast.

Two spore types were used to indicate the distribution of spores liberated in dry daytime weather, total pollen (predominantly from grasses) and the lighter conidia of Cladosporium, a common saprophytic fungus. Concentrations of Sporobolomyces, Tilletiopsis, ascospores and hyaline basidiospores, were combined as an example of spores liberated in damp air, commonly at night.

Paired profiles are plotted in Fig. 2 on a linear height scale and a logarithmic scale for spore concentration (Hirst et al. 1967). To prevent confusion, the origin for each curve is displaced and lettered to correspond with those at the base of the profiles in order of increasing distance from the coast. Few of the profiles were as simple as those typical of unstable air (Hirst et al. 1967). In most, spores were fewer in the lowest samples than at $450 \mathrm{~m}$. because they were deposited from the lower stable layer. This erosion was greater with pollen than with Cladosporium profiles, presumably because pollens are heavier and settled faster. The greatest spore concentration usually occurred between the inversions, at heights ranging from 450 to $1070 \mathrm{~m}$., but consistently some Cladosporium and pollens also occurred above the upper inversion. Pollen grains in each of these strata were always most concentrated below the altitude of the greatest concentration of Cladosporium.

Further consideration of the profiles in Fig. 2 led to the surprising conclusions summarized in Fig. $3 a$, where the estimated concentrations in each profile were summed and expressed as a percentage of the greatest. For each spore group, the concentration 
$10^{3} \mathrm{ft} . \mathrm{km}$.
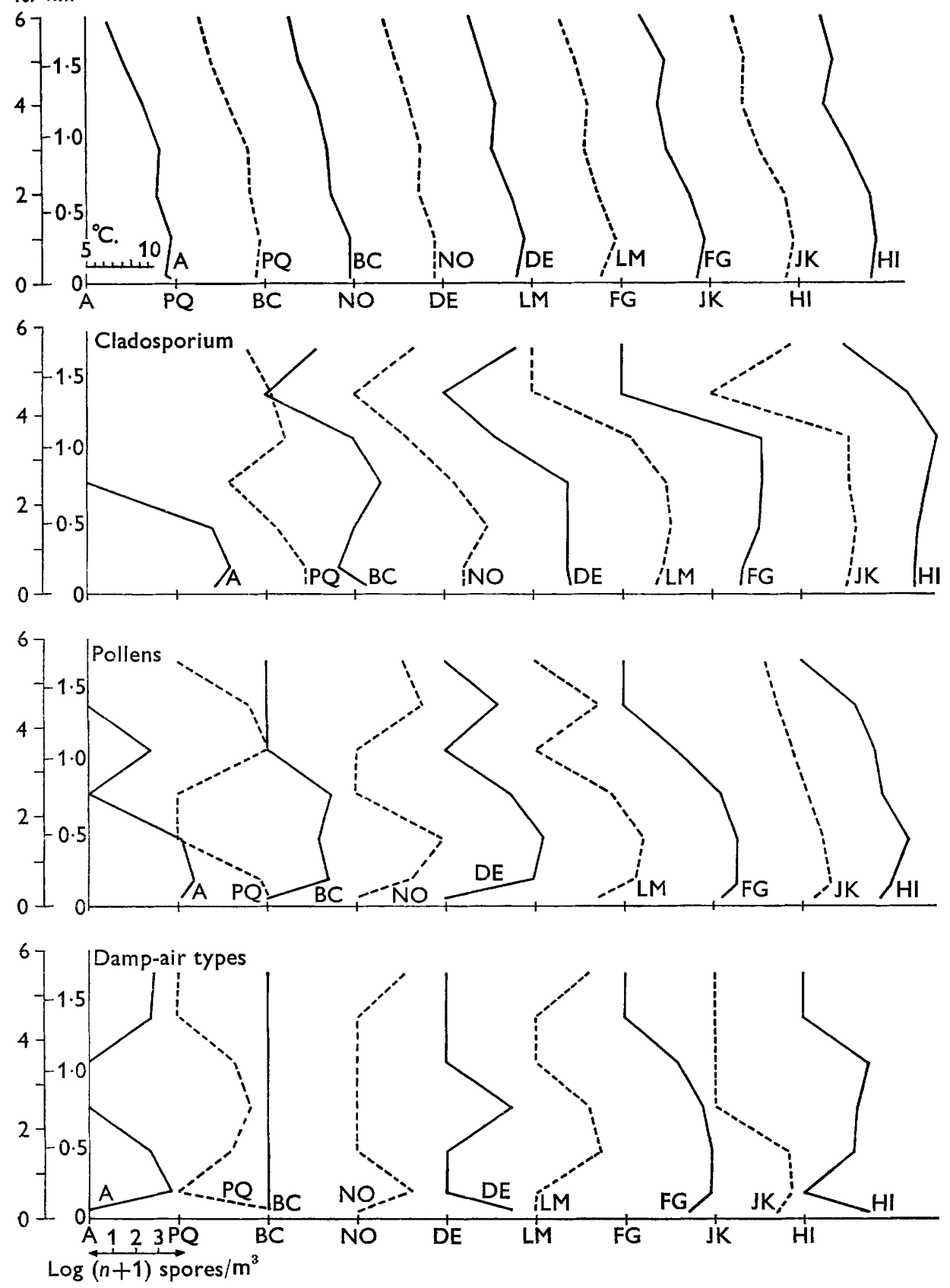

Fig. 2. Vertical profiles of temperature and concentration of Cladosporium, pollen and damp-air spores in Flight I/62, I5 June 1962. Profiles (except A) are average in pairs as shown in Fig. I $b$ and plotted with their origins (lettered below axis) displaced to the right approximately in proportion to distance of lowest sample from the coast. Profiles for the outward track in solid lines and for return track dotted lines. 
decreased for the first 70 miles from the coast and then increased again to peaks about I 70 miles out (Fig. $3 a$ ). The lower panel shows the height at which the maximum concentration occurred in the paired profiles at each distance from the coast. The height of the greatest Cladosporium concentrations increased as distance from the coast increased; pollen concentrations did not show a comparable trend. This spore distribution cannot be explained in terms of the typical decrease in concentration of spore clouds as they travel away from sources.
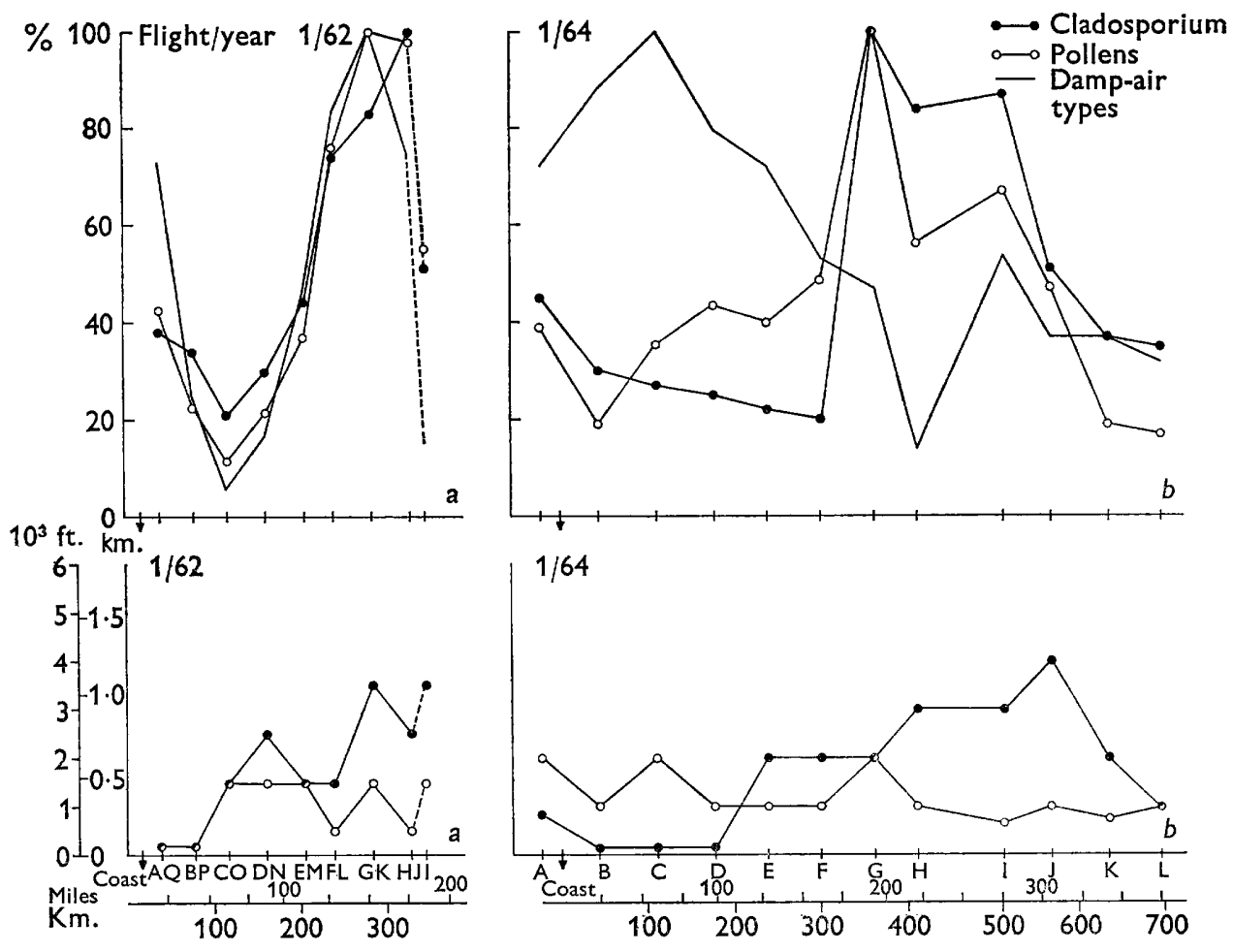

Fig. 3. Upper panels show sum of estimated concentrations within profiles (expressed as percentages of the greatest) and indicate that numbers of the three marker groups were greatest between 50 and 200 miles from the coast, both in Flight I/62 (left) and Flight I/64 (right). The lower panels show the heights at which the maximum concentration of Cladosporium and pollen occurred in relation to distance from the English coast.

Sequences of vertical profiles, like those in Fig. 2, give little impression of the form of the spore clouds they represent, so contoured diagrams of spore concentration were prepared. The estimated spore concentrations were plotted on a grid, showing height and distance within the vertical section and then lines ('isospores') were drawn through regions of equal spore concentration (Fig. $4 a$ ), and to accommodate the wide range of concentrations, the values of these lines were separated on a geometric progression increasing by a factor of two ( $\log _{2}$ scale). In this diagram the outward and inward profiles at the same position were paired, not neighbouring profiles on the same flight path as in Fig. 2. Catches from ascent ' $I$ ' were therefore unpaired and as they suggest rather abrupt changes the isospores are shown dotted in this area. All three indicator groups were commoner near the coast than about 70 miles off-shore and all 
were commonest about 150 miles out. Pollens were commonest at approximately $500 \mathrm{~m}$. and Cladosporium at $1000 \mathrm{~m}$. The similar distribution of pollens and 'dampair types' was unexpected, because close to the ground they become common in quite different conditions.

The spores found concentrated at the north-east end of the flight could have come
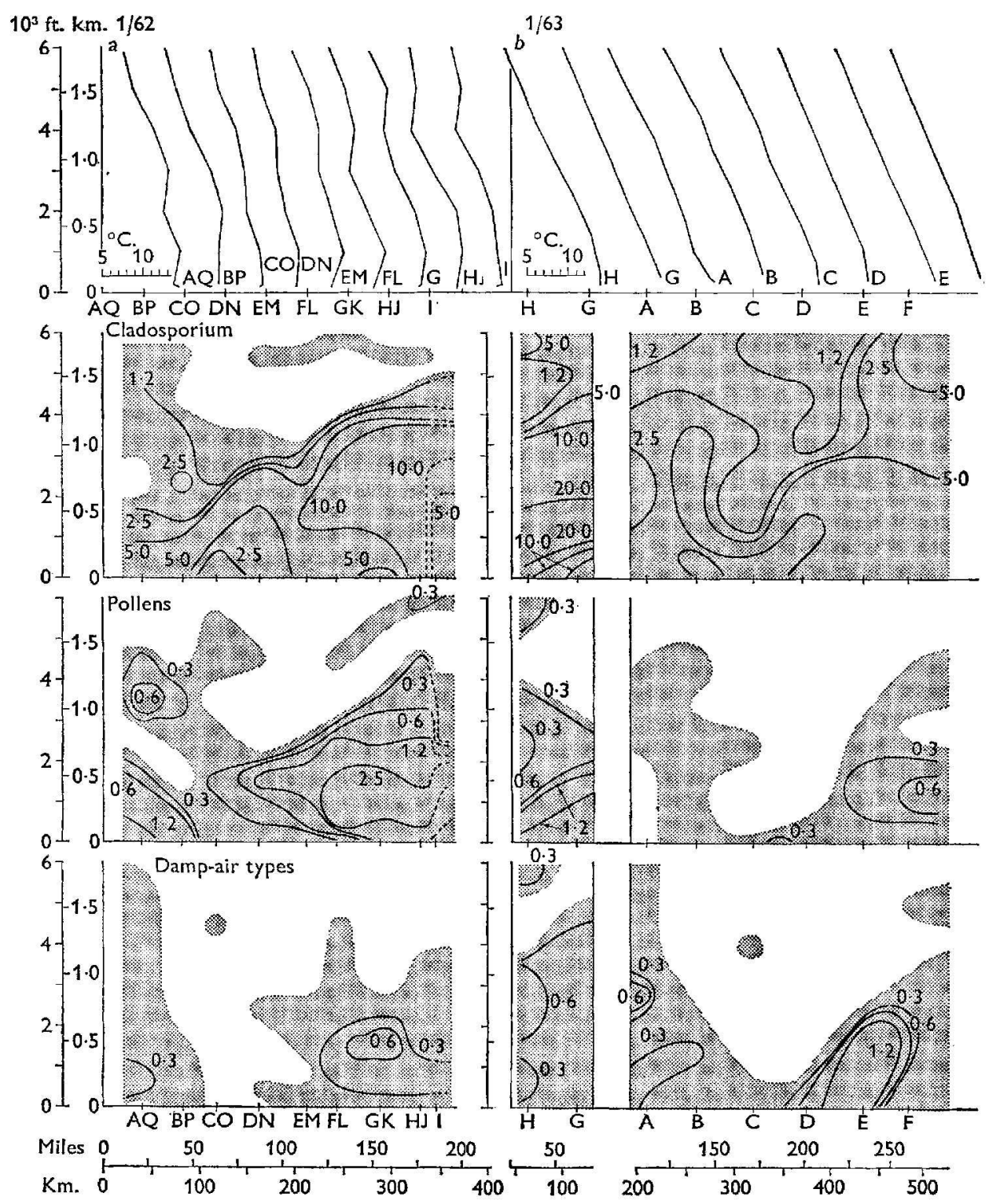

Fig. 4. Vertical temperature profiles (top), with the lettered origins displaced according to distance from the coast, Flight $1 / 62$, left, and Flight $1 / 63$, right. Below, isospore diagrams showing the distribution of marker spore types with height and distance. Shaded where any spores were detected, isospore lines separated on a geometric progression increasing by a factor of two, and marked in hundreds of spores $/ \mathrm{m}^{3}$, for explanation see text. 
either from England or the Netherlands. Synoptic maps (Fig. I $a$ ) suggested that the Netherlands was not a likely source and a surface air trajectory from I ran back to south-west England the previous day. Average diurnal periodicities of concentration of the three indicator groups near the ground (Fig. I $c$, inset and Hirst, 1953) show that Cladosporium and pollen are commonest between 09.00 and 18.00 when convection is usually most active. From this knowledge, the probable source area of Cladosporium and pollens at the north-east extremity of the flight is indicated by the stippled land area within the zone of probable vector error in Fig. I $c$, it comprised much of southwest and central England. Comparable back-tracking from the south-west extremity of the flight path at 10.00 and I2.00, I5 June, suggested small areas of north-west France and south-east England as the probable sources. Over south-west England on I4 June the air was probably unstable up to $1000 \mathrm{~m}$., as a radiosonde ascent from Camborne, Cornwall, at 12.00 , showed a dry adiabatic lapse rate from the surface to about $600 \mathrm{~m}$. with maximum temperature of $18{ }^{\circ} \mathrm{C}$ on the coast and $23^{\circ}$ inland. On 15 June the midday radiosonde from Hemsby, Norfolk, also revealed convection to about $1000 \mathrm{~m}$. with a maximum temperature of $24^{\circ}$. The observed distribution of pollen and Cladosporium spores agreed well with this analysis and therefore supported the supposition that, near the coast, the aircraft sampled spores produced locally that morning (I 5 June) and perhaps in France the previous day, but that in the distant half of the track the aircraft moved into the spore cloud produced over south-west England on I4 June.

Had damp-air types followed their usual periodicity, they should have alternated, rather than coincided, with the dense portions of the pollen and Cladosporium spore clouds, provided that they remained suspended in air near the ground long enough to experience convection the following morning. On this occasion air sampled at ' $I$ ' should have almost cleared the Norfolk coast by o0.0I, I June, before night-liberated spores would usually be prevalent. Air sampled slightly farther west at GK would probably have crossed the coast later and farther south and east; more spores would be expected here and more were found. At the south-west end of the flight path some spores were found and could have come from south-east England earlier that morning, but had they done so, even more damp-air spores would have been expected at points on Fig. 4 between $\mathrm{CO}$ and EM but there were none, a lack unexplained by the catches.

In this flight, spore concentrations were not large, with Cladosporium and pollens most common and next Ustilago (maximum $4 n 0 / \mathrm{m}^{3}$ at $600 \mathrm{~m}$. in ascent $\mathrm{G}$ ), which was distributed similarly to Cladosporium. Other dry-air liberated spores included Alternaria, Botrytis, Epicoccum, Erysiphe, Polythrincium and Torula, but they were few. Ascospores were the commonest of the damp-air groups occurring up to $1800 \mathrm{~m}$. in most profiles, and others were occasional.

\section{Flight I/63; II.55-14.45 G.M.T., 17 July 1963}

A flight twice as long as Flight I/62 was planned in the hope it would pass through the spore clouds of more than one day, but the range of the aircraft was not enough to use the saw-tooth flight plan on both the outward and return legs. To keep well clear of the Dutch coast a downwind track (Fig. 5 b) of $070^{\circ}$ was flown from Flamborough Head, but unfortunately $8 / 8$ stratocumulus cloud and rain prevented sampling for the first 100 miles; thereafter sampling was continuous to a position about 20 miles west of Esbjerg in Denmark. On the return leg towards Cromer, Norfolk, samples 
were taken only during a single descent and ascent within 100 miles of the coast, in an attempt to compensate for the loss of samples on the outward flight. The concentrations measured in profiles $\mathrm{G}$ and $\mathrm{H}$ did not match those in $\mathrm{A}$ but both are presented in Fig. $4 b$ to illustrate differences existing only 100 miles and $3 \mathrm{hr}$ apart. Temperature profiles (Fig. $4 b$ ) showed that air was unstable up to approximately $2000 \mathrm{~m}$. above which there was stable air marked by a 'haze-top'. Spore concentrations were small on the outward leg, maxima $970 / \mathrm{m}^{3}$. for Cladosporium and $90 / \mathrm{m}^{3}$ for pollens in ascent $\mathrm{F}$, and $200 / \mathrm{m}^{3}$ for the group of damp-air types in descent $\mathrm{E}$, all beneath $760 \mathrm{~m}$. More were caught on the return leg, with maximum concentrations in ascent $\mathrm{H}$ of respectively 3600 , 170 and $110 / \mathrm{m}^{3}$ for the three groups.

The flight was made in a rather cloudy, maritime polar, west-south-westerly airstream, behind a cold front that had cleared England in the early hours and reached Denmark by midday on 16 July. No other fronts affected the British Isles until $06.00,17$ July, when rain reached much of Ireland and Scotland (Fig. $5 a$ ) but was too late to affect the air sampled during this flight. Air-flow was uniform in direction up to $2500 \mathrm{~m}$. and saturated adiabatic lapse rate occurred up to inversions at $2500 \mathrm{~m}$. at Liverpool and I500 m. at Camborne at both I2.00 and 23.59, I6 July. During the flight, at 12.00 , I7 July, there was a dry adiabatic lapse rate up to $1500 \mathrm{~m}$. and an isothermal layer above at Hemsby; temperatures taken over the sea in flight showed a stable layer just a little higher than the highest samples shown in Fig. $4 b$. Air trajectories were therefore estimated at $850 \mathrm{mb}$. (about $1500 \mathrm{~m}$.) where winds were generally from the south-west at 20 knots $\left(37^{\cdot} \mathrm{I} \mathrm{km}\right.$./hr) or less (Fig. $\left.5 b\right)$.

Assuming, as in the analysis of Flight $\mathrm{I} / 62$, that Cladosporium and pollens would most commonly be liberated and ascend between 09.00 and 18.00 , an attempt was made in Fig. $5 c$ to depict how the duration of daytime overland travel was related to the flight path. This track forms the lower margin of the hollow polygons and distance from it indicates the proportion of the period 09.00-18.00, I6 July, for which the air was estimated to have been over land. The small black triangle, displaced from the flight path, indicates the local contribution from Norfolk on the morning of I 7 July. Thus more Cladosporium and pollen was expected near the west end and at the eastern extremity of the outward flight, and the trajectories suggest that spores represented by the left-hand polygon came from Ireland and by the right-hand polygon came from England and Wales. In a cool maritime polar air mass it is neither surprising that catches were rather small nor, in view of the instability up to $1800 \mathrm{~m}$., that spore concentration varied so little with height. More spores were found in profiles $G$ and $H$ and they could have come from sources in Ireland during daytime on I6 July and eastern England early on $\mathrm{I} 7 \mathrm{July}$. The greater catches in $\mathrm{H}$ than A perhaps resulted from longer travel over England and particularly over East Anglia on the morning of 17 July.

Except during or after rain, the damp-air types are liberated most frequently from 22.00 to 06.00 . Thus, on the outward course, the number of damp-air spores derived from England on the night 16-17 July would be expected to increase betwen A and C and then to decrease to nothing at F, but most occurred at A, E and F. Spores at E could have come from Ireland on the night of I5-I 6 July, but their origin cannot be determined certainly and it is also unknown how much the concentration of these and other spores was decreased by rain wash near the English coast. Interpretation was also made difficult by Ireland and England behaving as tandem sources. 

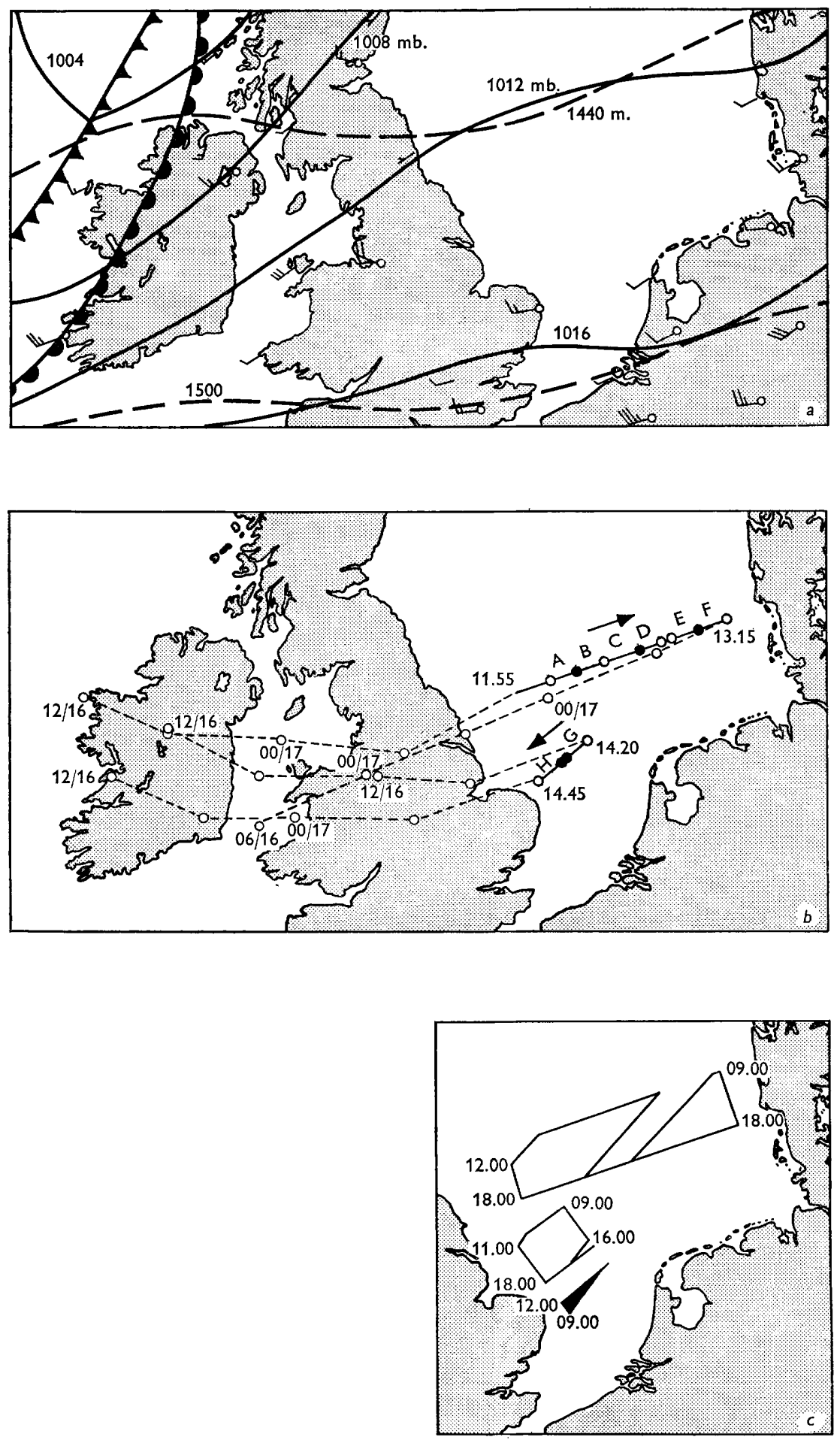

Fig. 5. For legend see opposite page. 


\section{Flight 2/63;09.47-I2.22 G.M.T., 3I July 1963}

When this flight was planned on 30 July I 963 southerly winds were expected to continue over the sea north of the Wash. However, easterly winds extended farther north than expected and occupied the whole of the flight path for 360 miles north from King's Lynn to a position approximately midway between Wick and Stavanger (Fig. $6 c, d)$. Thus the flight provided a cross-wind section up to $1800 \mathrm{~m}$., instead of measuring depletion of spore clouds downwind. The return flight was on a reciprocal course at $\mathrm{I} 800 \mathrm{~m}$.

Except near the coast (A and B, Fig. 7) temperature lapse rates were small or negative in the lowest $300 \mathrm{~m}$. and also above $1500 \mathrm{~m}$. in profiles $A$ to E. Thereafter the base of the upper stable layer descended to mark a strong inversion at $900 \mathrm{~m}$. $(\mathrm{J}, \mathrm{K})$ and finally rose to approximately $1500 \mathrm{~m}$. at the northern extremity of the flight. The isospore diagram (Fig. 7) shows a considerable concentration of Cladosporium below I000 $\mathrm{m}$. near the Wash (A and B), and beyond this, concentrations were small until $\mathrm{K}$ to $\mathrm{O}$. Smaller spore concentrations occurred at the temperature inversions of the upper stable layer, between $\mathrm{L}$ and $\mathrm{O}$, than above or below. Pollen is not shown on Fig. 7 because few were caught and they were distributed similarly to Ustilago. Erysiphe, Epicoccum, Polythrincium, Entomophthoraceae, Helicospores and Venturia inaequalis occurred sporadically; Alternaria and Botrytis were more common (max. I60/ $\mathrm{m}^{3}$ ). The damp-air group occurred widely but was common only in profiles $\mathrm{B}$ and $\mathrm{L}$ to Q. Ascospores $\left(\max .580 / \mathrm{m}^{3}\right)$ and hyaline basidiospores $\left(\max .670 / \mathrm{m}^{3}\right.$ ) were most common in ascent $\mathrm{Q}$, whereas most Sporobolomyces $\left(\max .670 / \mathrm{m}^{3}\right.$ ) and Tilletiopsis (max. 250/m. ${ }^{3}$ ) occurred at A, B and M. A few Puccinia graminis uredospores were caught in samples indicated by large dots on Fig. 7 (Cladosporium). On the outward flight I 4 uredospores were caught in I I samples, representing a mean concentration of $3 / \mathrm{m} .^{3}$ and including a maximum of $60 / \mathrm{m}^{3}$ in one sample. During the return on the reciprocal course at $1800 \mathrm{~m}$., 5 uredospores were caught in 20 samples representing an average concentration of about $6 / \mathrm{m}^{3}$.

Synoptic charts for the surface and $700 \mathrm{mb}$. levels are shown for 3I July (Fig. 6a,b) and examination of these and earlier charts was supplemented by information from radiosonde ascents and the occurrence of 'sferics' (long wave radio emissions from lightning flashes, see Handbook of Aviation Meteorology, I960, p. I83). Pressure was high over north-west Russia with a ridge across Norway towards England and a shallow thundery trough over the Baltic. Less confidence can be placed in the trajectories drawn for this flight (Fig. $6 d$ ) than for others, because the flight path was close to the line of the ridge where wind speed and direction were difficult to determine. The alternative possibility that the track lay just to the west of the ridge line was investigated but the general pattern of movement from the Eastern Baltic during the night of

Fig. 5. Weather and flight details of Flight $1 / 63$. (a) Weather situation at 00.01 , I7 July 1963. Details as for Fig. I $a$ but dashed lines represent $850 \mathrm{mb}$. contours and winds at this height (approximately $1500 \mathrm{~m}$.). (b) Flight track in solid lines with direction arrowed and four figure times. Letters indicate sloping profiles, hollow circles are high-points and solid circles are near the sea. Dashed lines show air trajectories at the $850 \mathrm{mb}$. level. Estimated positions at $6 \mathrm{hr}$ intervals are shown but only $12 \mathrm{hr}$ intervals are marked with hour/date. (c) Diagram showing the estimated proportion of the period $09.00-18.00$ spent overland by the air sampled at various points along the flight track. For explanation see text. 

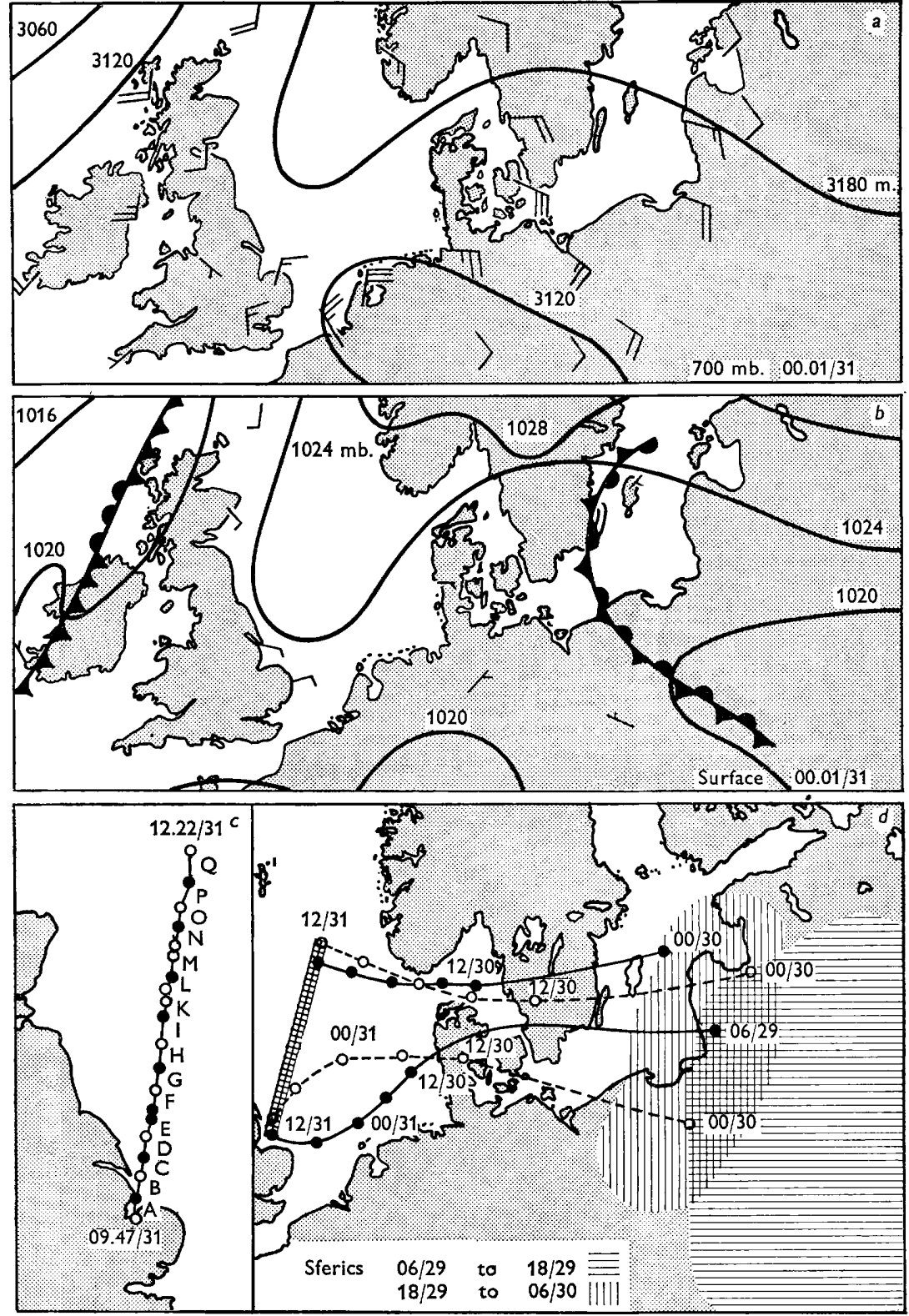

Fig. 6. Weather and details of Flight 2/63. (a) $700 \mathrm{mb}$. contours and winds at $00.0 \mathrm{I}, 3 \mathrm{I}$ July 1963. (b) Surface weather map for 00.0I, 3I July 1963. (c) Flight track with times and positions of profiles lettered, hollow circles were highest samples and solid circles were nearest the sea. (d) Flight track (shaded) and air trajectories to its extremities at 'surface' (approximately $500 \mathrm{~m}$. in solid lines and circles) and at $700 \mathrm{mb}$. level (dashed line and open circles). Line shading indicates areas from which 'sferics' were detected at times and dates shown. 
$10^{3} \mathrm{ft} . \mathrm{km} . \quad 2 / 63$
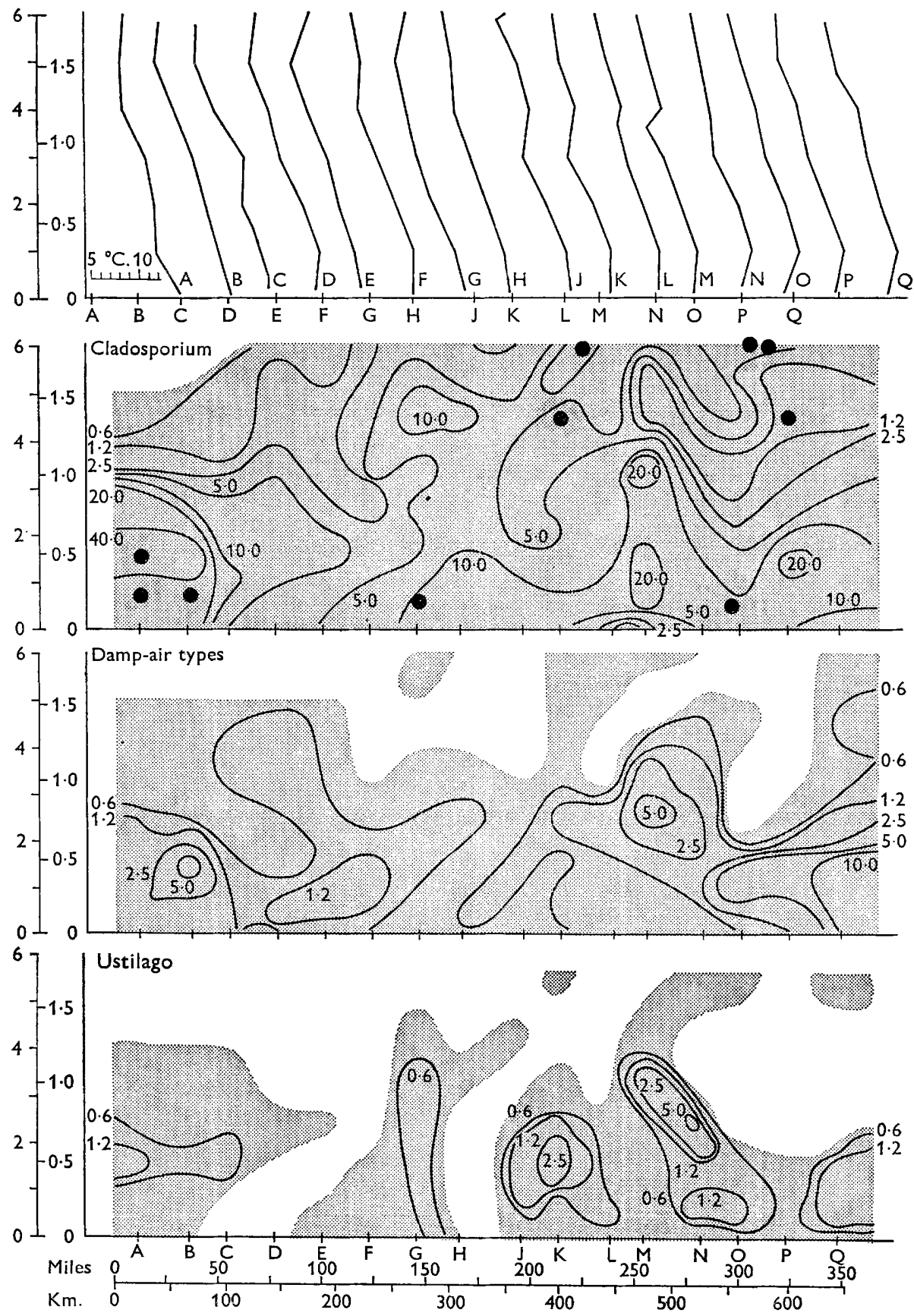

Fig. 7. Vertical temperature profiles (top) and isospore diagrams of Cladosporium, dampair types and Ustilago in Flight $2 / 63$ (details as Fig. 4). There were too few pollens and Puccinia graminis uredospores to show on separate diagrams but presence of the latter is indicated by black circles on the Cladosporium diagram. 

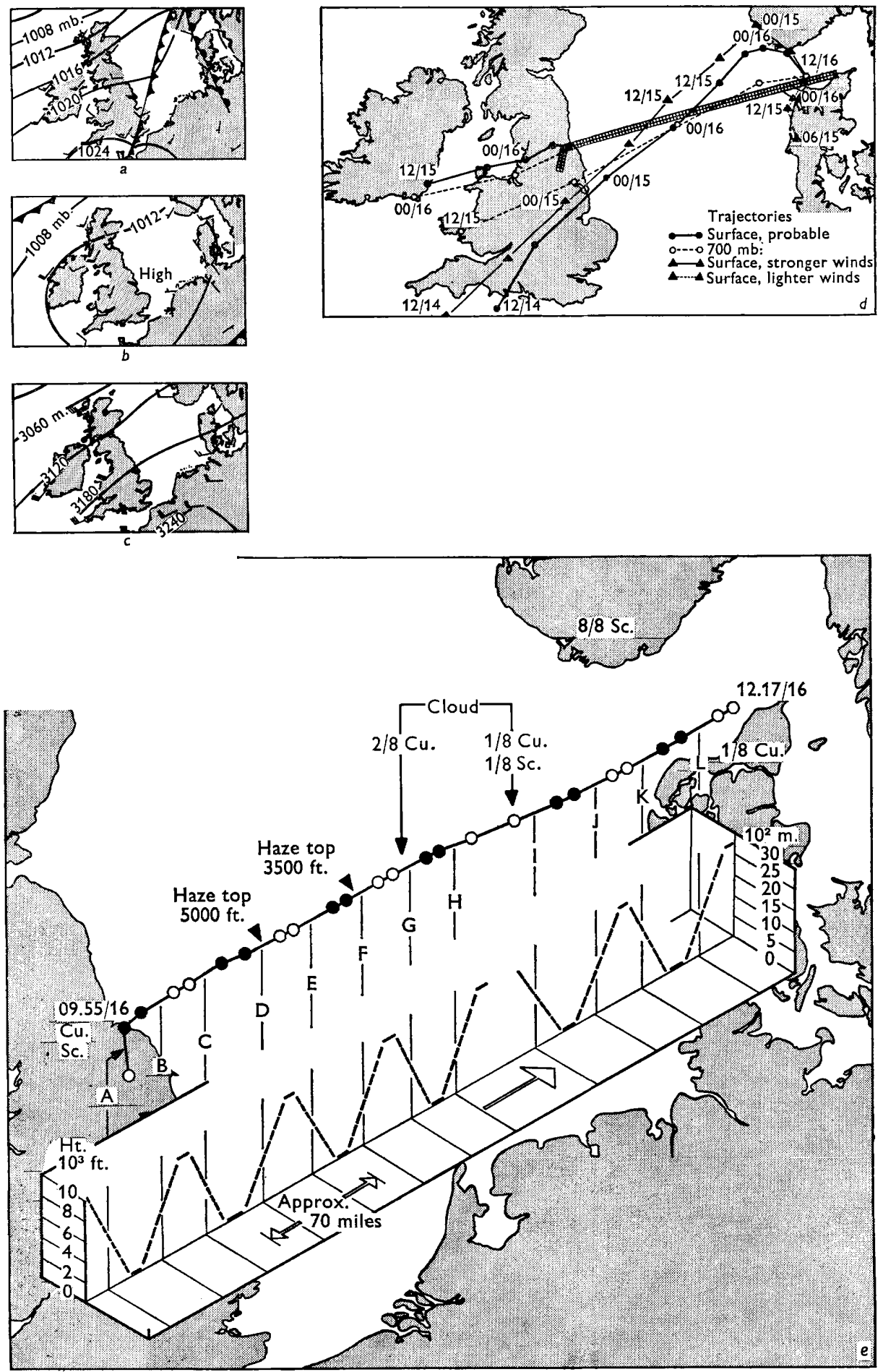

Fig. 8. For legend see opposite page. 
29-30 July remained valid. In this area during the preceding $24 \mathrm{hr}$ widespread sferic activity indicated vigorous convection and thunderstorms, which could have distributed spores favourably for distant transport.

The temperature profile measured from the aircraft during A was confirmed by the I2.00 radiosonde ascent from Hemsby, which revealed stability between $300 \mathrm{~m}$. and $600 \mathrm{~m}$. and above $1500 \mathrm{~m}$. The temperature profile measured during $\mathrm{Q}$ also agreed closely with that measured upwind at Sola, Norway, where stable air below $300 \mathrm{~m}$. gave place to unstable air up to about $3000 \mathrm{~m}$.

Scarcity of information from possible source areas, the probability that spore concentrations may have been modified by precipitation, and doubts about trajectories combine to limit the conclusions that can be drawn from this flight. The distribution of Cladosporium and Puccinia graminis uredospores suggests they may have come from the same places but it is surprising that Ustilago, which is also commonly derived from grasses and cereals, was commonest beneath the inversion at 900-I $200 \mathrm{~m}$. between $\mathrm{L}$ and $\mathrm{O}$. The scarcity of pollens is not surprising because little was probably liberated during the thundery weather in possible source areas. The reasons for the relative scarcity of spores in the southernmost third of the flight, the prominence of dry-air types above $600 \mathrm{~m}$. in the centre and of damp-air types at the northern extremity, remain unexplained. The spore profiles and isospore diagrams seemed closely related to temperature distributions; the smallest concentrations occurred in the isothermal layer above $1500 \mathrm{~m}$. at A and B, directly above the greatest concentration of Cladosporium. Proximity suggests these could have come from East Anglia but with stable air just above $300 \mathrm{~m}$. both during the flight and at Hemsby it is difficult to see how so many could have risen so far so quickly; also the $P$. graminis uredospores accompanying them are most unlikely to have come from this area.

$$
\text { Flight I/64; 09.45-I2.15 G.M.T., I6 July } 1964
$$

During this flight sampling began with a descent, A, from near York to Redcar and then on a track of $060^{\circ}$ for about 400 miles into the Skagerrak. The flight was again of 'saw-tooth' pattern but the ascents to $2700 \mathrm{~m}$. were higher than previously (Fig. 8e). The pilot reported well broken cloud with a haze top at $\mathrm{I} 500 \mathrm{~m}$. in the west and about $1000 \mathrm{~m}$. farther east. These observations agreed with the irregular temperature profiles at the start of the flight but towards the centre the profiles suggested that the haze top was probably diffuse.

Few spores were caught above $1800 \mathrm{~m}$. so the isospore diagram (Fig. 9) is limited to this height. It shows large Cladosporium concentrations near the start, mostly below $900 \mathrm{~m}$., fewest about 150 miles out, followed by unusually large concentrations centred $1000 \mathrm{~m}$. above sea level and 175-275 miles from the English coast (see also

Fig. 8. Weather and details of Flight 1/64. (a) Surface chart for 12.00, I5 July I964. (b) Surface chart for I2.00, I6 July 1964. (c) $700 \mathrm{mb}$. chart for I2.00, 16 July 1964 . (d) Flight track shaded and air trajectories to near each end at 'surface' and at $700 \mathrm{mb}$. level. Additional surface trajectories marked with triangles show the effect expected from winds both stronger and weaker than those assumed in the probable trajectory (see text). (e) Composite diagram showing, above, the track of Flight I/64 and below, an isometric diagram of the saw-tooth flight plan. Open circles indicate high-points and solid circles near the sea, letters indicate ascents and descents and refer to the diagram below where each dash represents a sample. 
Fig. 3 b). Pollen was most concentrated $600 \mathrm{~m}$. high and at 190 miles from the coast. By contrast, the damp-air types were most numerous in two discrete areas, on either side of the main Cladosporium cloud, respectively 50-I25 and 300-350 miles from the coast.

From I4 July pressure was high from Spain to Central Europe and fronts that crossed the British Isles on I 4 and early I 5 July were followed by rising pressure (Fig. $8 a$ ).

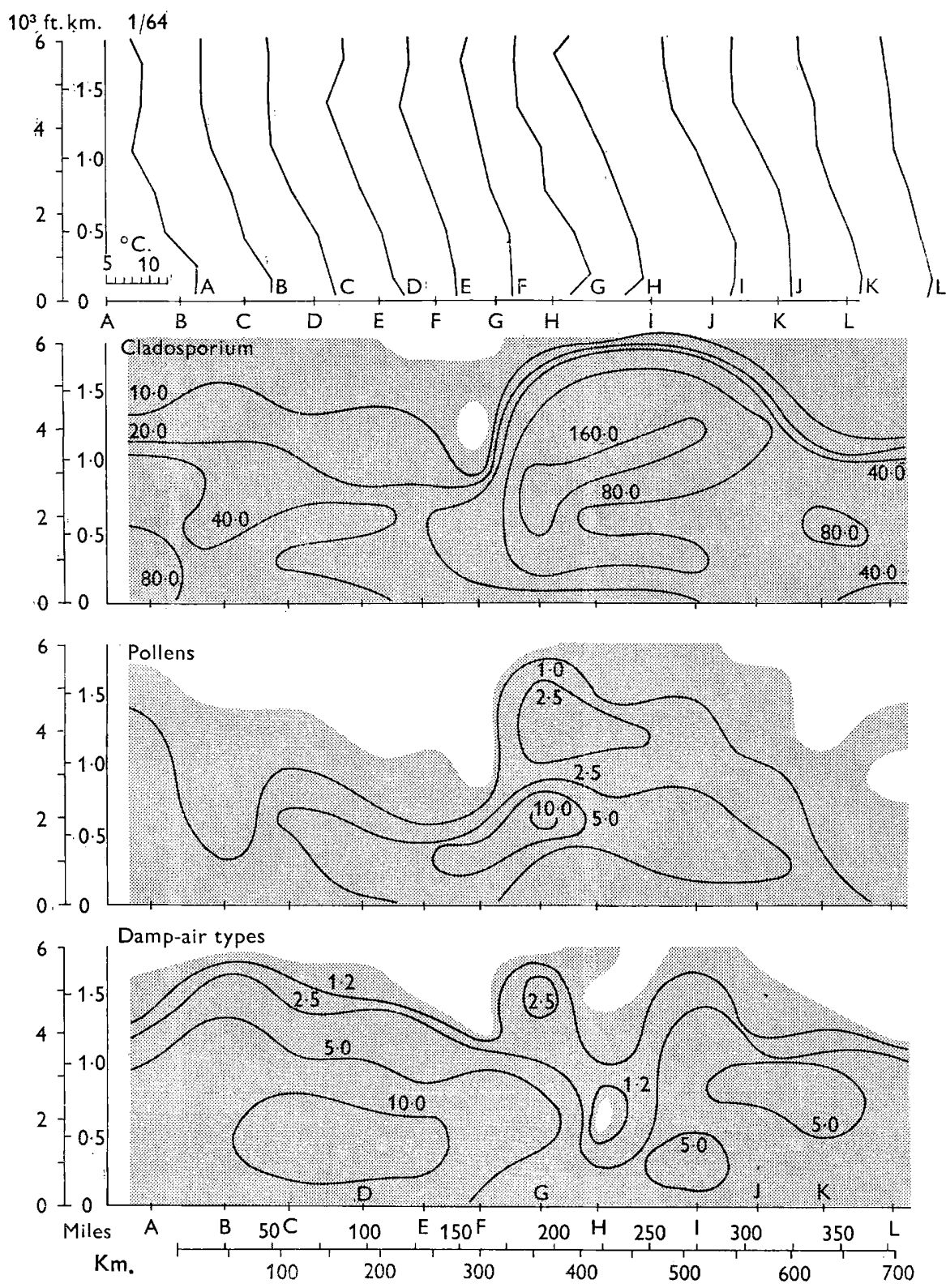

Fig. 9. Vertical temperature profiles (top) and isospore diagrams of Cladosporium, pollen and damp-air types in Flight $\mathrm{I} / 64$ (details as Fig. 4). 
A fairly definite south-westerly surface airstream on I 5 July gave place by 16 July to lighter and more variable winds (Fig. $8 b$ ), which made back-tracking uncertain at low level although it could be done more reliably at $700 \mathrm{mb}$. (approximately $3000 \mathrm{~m}$., Fig. $8 c$ ).

At first an attempt was made to explain the observed spore distribution by low-level winds. At the Yorkshire coast at 10.00 on I6 July, surface air would have crossed England after midnight (Fig. $8 d$ ), so the dense Cladosporium cloud low over the land near A could have been liberated east of the Pennines that morning. Spores liberated the previous day in North Wales or the south coast of Ireland may also have contributed to the cloud. Forced lifting by air flowing over the Pennines may have helped to disperse these spores upwards. Between $\mathrm{C}$ and $\mathrm{E}$ (Fig. $8 \mathrm{c}$ ) trajectories suggested that surface air would have crossed England and Wales by night, and there were least dry-air types and most damp-air types in this region. Day-liberated spores would have been expected to be most common between $\mathrm{E}$ and $\mathrm{G}$, and concentrations did increase in this region but much of each spore cloud was further east. Few damp-air types would be expected in the area just beyond the mid-point, and few were found. Again few night-liberated spores were expected or found at the eastern extremity $\mathbf{L}$, suggesting that the South coast of Norway was not an important source. Some day-liberated spores released from southern England during the afternoon of I4 July might have reached $\mathrm{L}$, but concentration did not increase there.

Spore distributions, particularly near the middle of the flight, were not adequately explained by low-level winds, so it was decided to consider higher winds. Upper air charts for $700 \mathrm{mb}$. showed that spores released from England and Wales the previous day would have reached the north-eastern end of the track by 12.00, I6 July (Fig. $8 d$ ). and air sampled at the mid-point would have crossed the land during the night. The discrepancies between the observed distribution and the distributions suggested by upper and surface winds were in different directions along the flight path, so it seemed possible that winds at an intermediate height might explain the observed distribution more accurately.

Over land the previous day, radiosonde ascents at Liverpool showed weak inversions between 900 and $1500 \mathrm{~m}$., but these were too shallow to prevent penetration by active convective bubbles, so with maximum surface temperatures of $20^{\circ} \mathrm{C}$ spores could easily have been lifted to $2000-2500 \mathrm{~m}$. and some possibly even higher. At $3000 \mathrm{~m}$. winds were often 3 to 4 times as strong as at the surface. The main wind shear occurred below $1500 \mathrm{~m}$. and between 1500 and $3000 \mathrm{~m}$. speeds differed by only 5-Io knots. It is therefore reasonable to assume that much of each spore cloud raised by convection on 15 July would have been carried east by winds intermediate in speed between those at the surface and those at $700 \mathrm{mb}$. Indeed the sloping axis of greatest concentration in the Cladosporium and pollen clouds is what would be expected from exposure to stronger winds at increasing height.

The flight was in a region of very light surface winds and much uncertainty existed, particularly at the eastern end, for the first few hours of back tracking. The probable surface track already mentioned assumed a moderate flow of about 6 knots, and winds of 8 knots would have made little difference (Fig. $8 d$ ) but very light winds ( $2-3$ knots) would have altered the source area to West Denmark early the previous morning (Fig. $8 d$ ). There the weather was dull with light winds and little convection, so the scarcity of day-liberated spores at the east end of the flight path was not necessarily 
evidence against an air trajectory from Denmark. Again assuming light winds, the air sampled at points farther west along the flight path would have come from Germany with less likelihood of high spore concentrations, but the diagrams show that dayliberated spores were more frequent here. Thus the distribution of spores in 'surface' air supports the theory that the British Isles were the source of the spores sampled even at $\mathrm{L}$.

\section{DISCUSSION}

Many airborne fungal spores were detected hundreds of miles downwind from land in each of these flights. As we tried to select dry weather for flights we can claim no more than that long-distance transport occurs frequently in summer. Such observations will be of limited value to plant pathologists until we know how many of the spores are viable. At present there is no satisfactory routine method for growing cultures from trapped spores of saprophytes, or testing viability of obligate parasites. Until these deficiencies are remedied we may learn something from laboratory experiments which simulate the heights, temperatures and durations of flight of spores.

Hirst et al. (1967) found that, at $3000 \mathrm{~m}$., spores were often too few to be detectable with 30-60 1. air samples. The saw-tooth flight plan therefore went high enough to detect most spores and provided a valuable compromise between range and flight duration. In interpreting the results we regarded the ascents and descents as though they were vertical profiles, but it must be remembered that in both the flight path was only $3^{\circ}$ from horizontal and that the liberties we took in interpreting profiles would be permissible only in long flights over the sea. 'Contouring' the density of spore clouds, by constructing 'isospore' diagrams of vertical sections above the sea, simplified the demonstration of quite well-defined spore clouds, although it distorted their shape in the diagrams by contracting distance I40 times more than height.

In retrospect, it is not surprising that clouds of day- and night-liberated spores produced from the British Isles should be detectable, downwind over the sea, I or 2 days later. But when, in Flight $\mathrm{I} / 62$, spores became more numerous as distance from the coast increased and, especially of Cladosporium, with increasing altitude, the reason was not immediately apparent. The explanation we propose is well supported by the meteorological analyses which assumed that spores were liberated at their usual time of day. In all flights attempts to track spore clouds back to their sources left some features unexplained; sometimes the trajectories were in doubt, distant sources did not always seem to have produced the expected number of spores at the usual times, or, in some flights, position, wind speed and direction made it difficult to identify source areas (for example, to discriminate between England and Ireland). Because of these difficulties many more flights would be required to prove the theory which now seems probably correct.

Most profiles showed sign of 'erosion' near the surface and the isospore diagrams showed maximum concentrations between 600 and $1200 \mathrm{~m}$., which were 2 to 4 times greater than those of the surface air below. The flights did not test how quickly deposition eroded spore clouds. Presumably the process is continuous, but, above land sources, is often masked by preponderant spore liberation. Slight support for this idea was given in previous ascents (Hirst et al. 1967) when erosion of pollen and Cladosporium profiles, although usually detectable, was greatest at night. The shape of vertical profiles measured from aircraft must depend on the activity of vertical mixing during spore ascent and transport, in addition to the rate of deposition. 
Thorough turbulent mixing did not occur during these flights, or spore concentrations would have been more nearly uniform with height.

The effects of temperature inversions seem complex, the simplest example is the limitation of upward spore transport by a pre-formed inversion. The development of inversions within existing spore clouds leads to more complicated profiles. Such inversions often develop close to the ground at night when convection is minimal, but spore deposition by settling or frictional turbulence may still proceed; thus the concentration of day-liberated spores is decreased, and most occur above the inversion, in the past erroneously interpreted as suggesting that spores accumulated above inversions (Rempe, I937). Similar effects accompany inversions common near sealevel by day, because the stable air decreases turbulent diffusion of spores downward to replenish the concentration in surface air diminished by deposition. Spore concentration also decreased within stable air well above ground (see Figs. 4-8). Irregular profiles would be expected to result from shearing between air strata moving differently in speed or direction (see Flight $1 / 64$ ).

Several flights provided evidence of gravitational stratification according to spore size. Pollen clouds were centred $300-600 \mathrm{~m}$. lower than those of Cladosporium which is liberated at about the same time of day and ascends similarly in convection (Hirst et al. 1967) but has a much smaller terminal velocity. Presumably both types of spore would be equally diffused downward by eddies and deposited continuously but a greater proportion of the pollen cloud would be lost because these spores would fall faster into the air near the surface and be deposited from it. In addition to this separation of the main pollen and Cladosporium clouds, Flight $\mathrm{I} / 62$ indicated a similar stratification in the few Cladosporium spores at $1650 \mathrm{~m}$. and about $300 \mathrm{~m}$. lower in the corresponding pollen profiles (Fig. 2).

The discovery of damp-air liberated spores at up to $1800 \mathrm{~m}$. is of particular interest. Although these spores can be liberated on wet days, we attributed them to nightliberation in periods when little or no rain fell on the British Isles. Diffusion of nightliberated spores would seldom be helped by active convection during the period of release, and over England frictional turbulence seems unlikely to raise them to this height. An alternative explanation, proposed by Hirst (I953) to explain an abrupt decline of spore concentrations near the ground soon after dawn, is that, because of their small size, many remain suspended near the ground until dispersed upwards by convection soon after dawn. This possibility could be tested by sequences of ascents at different times of day and night, but we have been unable to repeat those made in I96I (Hirst et al. 1967) when too few damp-air spores were caught to construct reliable profiles. Nor do we yet know enough of the biology of the organisms to say whether those disseminated are wasted or whether smallness is an advantage, which by delaying deposition allows distant transport of night-liberated spores.

Although we do not know whether spores can be carried across the Atlantic, it seems safe to assume that only a few would remain in trans-Atlantic air approaching the British Isles. To study depletion of spores over the North Sea we needed winds between south and west, and except for the British Isles, North-west France was probably the only potential European source of spores caught in Flights $1 / 62,1 / 63$ and I/64.

Uniform spore concentrations would occur at the downwind coast of a great land mass liberating spores at a constant rate. However, Cladosporium and pollens are 
liberated chiefly between 09.00 and 18.00 and our flights were made downwind of an island source which winds often crossed in Io or $12 \mathrm{hr}$. Therefore the day-liberated spores would be carried clear of the downwind coast during the night to cross the sea as a discrete cloud, the origin of which could be determined. Spores released between $\mathbf{2 2 . 0 0}$ and 06.00 would alternate with but partly overlap the day-liberated spore clouds. Clouds released daily from larger sources or with slower winds would not be discrete, whereas smaller sources or faster winds would not allow such large concentrations of spores to accumulate and so would make the clouds less easy to recognize.

Though we were fortunate in working from an island source with size and winds apparently near the optimum for distinguishing daily spore clouds, the variability of spore concentrations leaving the coast seriously interfered with the original purpose of the flights, which was to measure the depletion of spore clouds. The proportion of spores deposited can only be measured when their initial concentration is determined by a sequence of ascents over the downwind coast. Without this information the rate of deposition cannot be measured by estimating the total spores represented by profiles at different distances from shore; neither can the shape of profiles, the maximum concentration nor the height at which this occurs be used, because these are continuously modified by erosion at the base and by turbulent mixing. Longer overland travel should make the spore clouds leaving the coast more uniform so that similar flights downwind of a continent might permit depletion to be measured accurately over greater distances.

Occasional eroded profiles have previously been reported, but our flights suggest they are typical remote from sources and also how they may arise. Depletion of spores in air near the surface has several important implications, because ground level spore traps must operate in a stratum partially depleted of far-travelled spores (see Hirst et al. 1967) and cannot be relied upon to measure accurately the concentrations passing overhead or even to show how this concentration varies with time. Until there are more measurements of atmospheric transport mechanisms, the relative contribution of distant and local sources to the catches of surface spore traps or to the diurnal periodicities of catches cannot be assessed. However, with westerly winds, the incursion of relatively spore-free Atlantic air is likely to influence diurnal periodicities of tropospheric spore concentrations considerably in the United Kingdom, and the effect may perhaps help to explain the difference among observations of Cladosporium periodicities in different parts of the world (see Hirst, I953; Hamilton, I959; Pady, Kramer \& Wiley, I962; Rich \& Waggoner, I962). Although we have rather few flights on which to report, the regularity with which many spores were detected far from land, together with previous interceptions (Hirst et al. 1967), suggests that long-distance transport is frequent during fine summer weather. The spores carried are so numerous that, if viable and effectively deposited by rain, even minor constituents of the cloud could have profound effects on crops.

We thank the staff of the Meteorological Office who have helped in this work; especially the Director General for permitting the flights and publication; Mr R. F. Zobel, then Head of the Meteorological Research Flight and his predecessor Dr R. J. Murgatroyd; also Mr J. F. Fisher and Mr S. G. Cornford. We are also grateful to Mrs Maureen Parker for technical assistance and for her care in preparing the diagrams. 


\section{REFERENCES}

Hamilton, E. D. (1959). Studies on the air spora. Acta allerg. 13, 143.

Handbook of Aviation Meteorology. (1960). M.O. 630 (A.P. 3340). London: H.M.S.O.

HiRst, J. M. (I953). Changes in atmospheric spore content: diurnal periodicity and the effects of weather. Trans. Br. mycol. Soc. 36, 375.

Hirst, J. M., STedman, O. J. \& HoGG, W. H. (1967). Long-distance spore transport: methods of measurement, vertical spore profiles and the detection of immigrant spores. J. gen. Microbiol. 48, 3 I9.

Pady, S. M., Kramer, C. L. \& Wiley, B. J. (I962). Kansas Aeromycology. I2. Materials, methods and general results of diurnal studies 1959-60. Mycologia 54, 168,

Rich, S. \& WAGgoner, P. E. (1962). Atmospheric concentration of Cladosporium spores. Science, N.Y. I37, 962 . 